\title{
Ureter Undifferentiated Carcinoma
}

National Cancer Institute

\section{Source}

National Cancer Institute. Ureter Undifferentiated Carcinoma. NCI Thesaurus. Code C6159.

Undifferentiated carcinoma that affects the ureter. 